\title{
Analysis of copper removal using different seafood wastes by differential pulse voltammetry (DPV)
}

\author{
Joel Ashervin Zachariaha, Mohd Rawa Ispal ${ }^{\mathrm{b}}$, Michelle Soo Oi Yoon ${ }^{\mathrm{a}^{*}}$ \\ a Aquatic Science Programme, Faculty of Applied Sciences, UCSI University KL, No. 1, Jalan Menara Gading, Taman Connaught, \\ 56000 Cheras, Kuala Lumpur, Malaysia \\ ${ }^{b}$ BioGenes Technologies Sdn. Bhd., Technology Incubation Centre, Infrastructure University Kuala Lumpur (IUKL), UniPark Suria, Jalan \\ Ikram-Uniten, 43000 Kajang, Selangor Darul Ehsan, Malaysia
}

Received 19th June 2020 / Accepted 25th January 2021

\begin{abstract}
Current methods of heavy metal removal are shown to have several drawbacks: cost of operation, generation of toxic sludge and complicated procedures in the treatment. In this study, the ability of seafood waste as a sustainable biosorbent was investigated. Three commonly consumed seafood wastes in Malaysia were chosen for this study: crab shells, prawn shells and cockle shells. This study aimed to determine the differences in copper removal between crab, prawn and cockle shells at fixed concentrations and weights of shells. Differential pulse voltammetry using a modified screen-printed electrode was used to determine the concentration of copper for each waste sample. Removal of copper was first observed at different shell weights between 20 and $100 \mathrm{mg}$ and at a fixed copper concentration of $20 \mathrm{ppm}$. Shell weights with the highest removal, $20 \mathrm{mg}$ and $40 \mathrm{mg}$, were then used for further observation at concentrations between 1-20 ppm. At a weight of $20 \mathrm{mg}$, prawn shells showed the highest removal percentage of copper at $34.40 \%$ while crab shells and cockle shells showed the highest removal percentage of $31.22 \%$ and $12.78 \%$, respectively. This was likely due to the presence of calcium carbonate and chitin as the main component in crab and prawn shells. Cockle shells showed low removal efficiency under these conditions. In conclusion, untreated crab shells and prawn shells were shown to successfully remove copper in water.
\end{abstract}

Keywords: copper, seafood waste, Malaysia, sustainability, biosorbent, screen-printed electrode (SPE)

\section{INTRODUCTION}

Copper is a reddish metal that occurs naturally in water, rocks and sediments. Copper enters the environment through anthropogenic sources such as mining and from factories that make or use copper metal or copper compounds. The according The WHO Guidelines for Drinkingwater Quality (2004) states that the acute lethal dose for adults lies between 4 and $400 \mathrm{mg}$ of copper (II) ion per $\mathrm{kg}$ of body weight. Metal finishing processes such as electroplating, etching, and preparation of metal components for various industries, have been identified as a major source of wastes containing high concentrations of copper in several states in Peninsular Malaysia (Shazili et al., 2006). Chemical precipitation, membrane separation, electrochemical

*Author for correspondence: Michelle Soo Oi Yoon, Faculty of Applied Sciences, UCSI University KL, No. 1, Jalan Menara Gading, Taman Connaught, 56000 Cheras, Kuala Lumpur, Malaysia. Email michellesoo@ucsiuniversity.edu.my 
deposition, ion exchange and reverse osmosis are regular processes for removing heavy metals from. However, these processes are fairly expensive and inefficient when heavy metal concentrations are less than $100 \mathrm{mg} / \mathrm{L}$ (Pugazhenthiran et al., 2015).

Seafood such as prawn, crabs and cockles are a well-loved delicacy in Malaysia. After meals, the leftover consisting of shells are often thrown away with garbage, ending up in landfills. This results in accumulation of seafood waste over time which results in odor and microbe pollution that eventually pollutes coastal environments thereby affecting marine life and the people who live in the vicinity. Various studies have shown that waste materials such as banana pith, corn cob, saw dust, date piths, rice husk ash, spent tea leaves, lemon peel, apple pomace and fruit peel are useful low-cost adsorbents (Sudha et al., 2014). Previous studies have shown that the adsorption properties of chitin have proven to be effective (Peiselt da Silva et al., 2004). Chitin's deacetylated form, chitosan has adsorptive properties that have been proven to be more effective than chitin.

Seafood waste could be utilized as a cheaper, sustainable alternative to treating wastewater containing heavy metals such as copper. The shells of crustaceans and bivalves have shown biosorption properties. Termed as adsorption, this is a physiochemical process that occurs in different types of biomasses, allowing it to passively concentrate and adhere contaminants onto its cellular structure (Kim et al., 2006). This method has been studied in a number of cases as a technique for heavy metal removal from water (Nascimento et al., 2019). The process does not depend on metabolism, since the metal ions accumulate on the surface of the biosorbents such as the seafood wastes. Therefore, with these in mind, we chose to study the biosorption efficiency of copper using three types of untreated seafood wastes: crab, prawn and cockle shells. In this study, screen printed carbon electrodes (SPCE) were used to determine the amount of copper in the solutions. The objectives of this study are to determine the differences in copper removal between crab, prawn and cockle shells at fixed concentrations and weights of shells.

\section{MATERIALS AND METHODS}

\section{Sorbent preparation}

The crab shells of Scylla spp., prawn shells of Penaeus spp. and cockle shells of Anadara spp., were collected from a seafood restaurant in Sungai Long, Cheras, Malaysia. The shells of the mentioned crustaceans were identified based on identification characteristics based on previous literature (Budin et al., 2014). The shells were boiled separately in distilled water in a $500 \mathrm{~mL}$ beaker for approximately two hours under a fume hood to remove the excess meat and seasonings on the shells as these shells were cooked prior to experimentation. No chemicals were used to pretreat the shells. The shells were placed on sheets of aluminum foil and dried in an oven at $60^{\circ} \mathrm{C}$ for an hour to remove moisture. The shells were then crushed using a pestle and mortar, and then sieved through a $0.5 \mathrm{~mm}$ pore size sieve to ensure the shell sizes were standardised (Figure 1) (Vijayaraghavan et al., 2011).

\section{Preparation of screen-printed carbon electrodes (SPCE)}

The SPCE's were purchased from BioGenes Technologies Sdn Bhd. The working electrode of the SPCE's were then rinsed with $10 \mathrm{~mL}$ of distilled water using a $10 \mathrm{ml}$ micropipette. The SPCE's were then left to dry in a plastic container. An amount of chitosan was mixed with an amount of acetic acid and was placed on a magnetic stirrer for two hours. The exact amount of chitosan used cannot be specified at the moment due to a confidentiality agreement with Biogenes Technologies Sdn Bhd. (Tang, 2019, pers. comm.). $10 \mu \mathrm{l}$ of the chitosan solution was then carefully drop-coated on the working electrode of the SPCEs. Once the SPCE's had been drop-coated, they were left in the plastic container to dry for 24 hours.

\section{Sorption experiments}

An initial test was done to determine the detection limit of copper on the screen printed carbon electrode with different copper concentrations $(20,40,60,80$ and $100 \mathrm{ppm})$. A pre-test was first conducted with a copper concentration of $20 \mathrm{ppm}$ with different weights of the shells to determine the shell weight with the highest sorption capacity. 
Initial readings of the copper solution were first taken by differential pulse voltammetry (DPV) using the SPE which was connected to a galvanostat (Metrohm Autolab PGSTAT101). The first batch of experiments were carried out in $100 \mathrm{~mL}$ conical flasks with different shell weights $(20,40,60,80$ and $100 \mathrm{mg})$. The prepared flasks were then sealed using parafilm to prevent evaporation. The conical flasks were then placed in a rotary incubator set at $30^{\circ} \mathrm{C}$ and $150 \mathrm{rpm}$ for 24 hours. The solution was then filtered through separate filter papers with pore sizes of $5-13 \mu \mathrm{m}$ to remove the shells and the filtered solution was analyzed to obtain the final readings. The following experiment was then repeated using the weight of shells obtained from the pre-test, which was then tested with different copper concentrations $(1,5,10,15$ and $20 \mathrm{ppm})$. The removal efficiency was calculated (formula given below) where $\mathrm{C}_{0}$, is the initial peak reading and $\mathrm{C}_{1}$ is the final peak reading. A multifactorial ANOVA was conducted for both sets of experiments.

$$
\%=\left(\frac{C_{0}-C_{1}}{C_{0}}\right) \times 100
$$

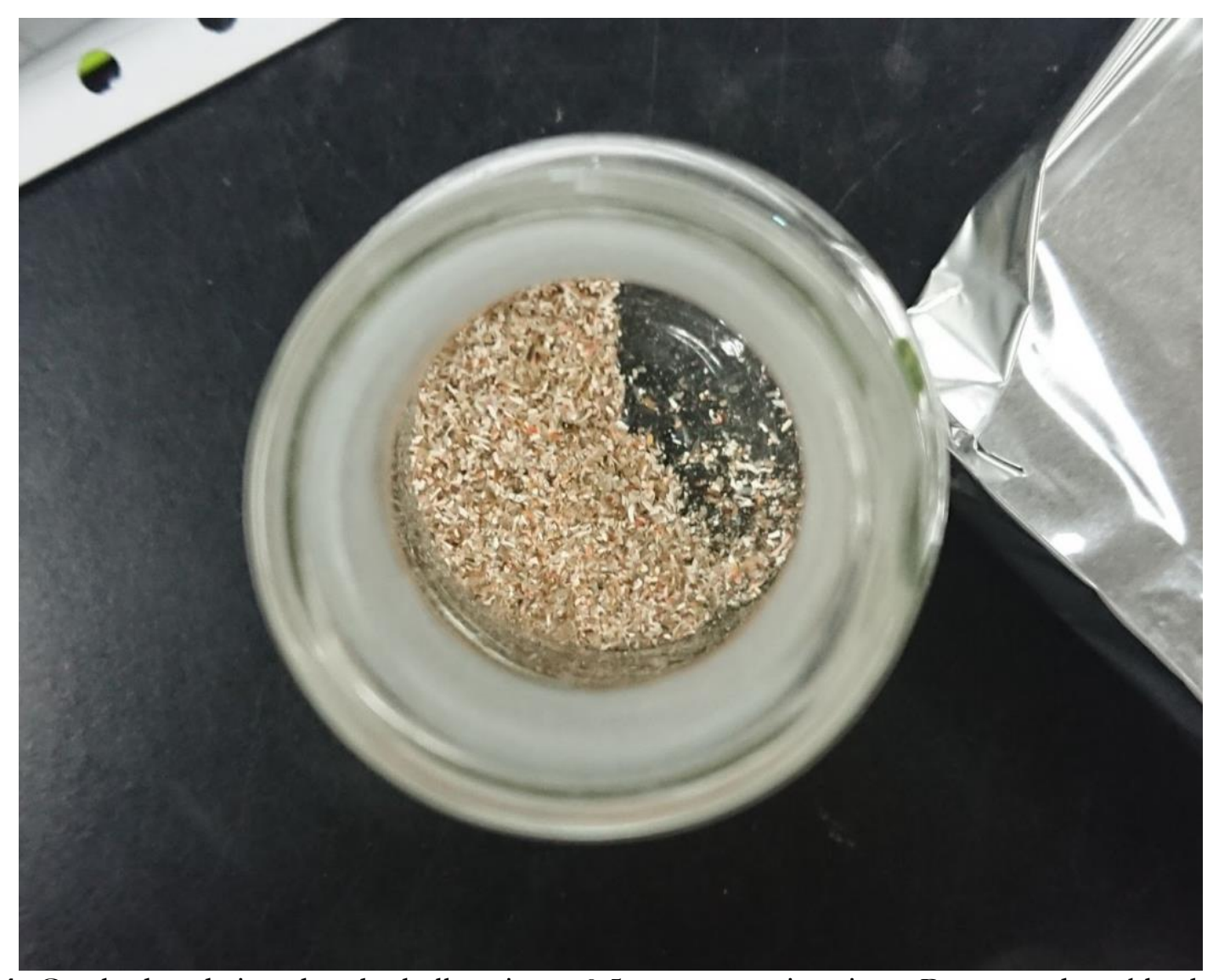

Figure 1. Crushed and sieved crab shells using a $0.5 \mathrm{~mm}$ pore size sieve. Prawn and cockle shells were also crushed and sieved to a size of $0.5 \mathrm{~mm}$ or less.

\section{RESULTS AND DISCUSSION}

The results showed that the readings beyond 20 ppm had shifted to the right beyond the range of copper which is usually between $-0.4 \mathrm{~V}$ and $-0.2 \mathrm{~V}$, indicating a detection limit (Figure 2). Thus the optimum concentration to be used in the pre-test was $20 \mathrm{ppm}$. The following phase was to narrow down and determine the shell weight, (20, 40, 60, 80 and $100 \mathrm{mg}$ ) with the highest sorption capacity. The highest removal percentage was observed at $20 \mathrm{mg}$ and $40 \mathrm{mg}$ (Table 1).

\section{Removal of 20 ppm of copper between shell weights 20, 40, 60, 80, $100 \mathrm{mg}$}

For crab shells, the highest percentage of copper removal was observed at $20 \mathrm{mg}$ and the lowest at 
$80 \mathrm{mg}$ of crab shells with removal percentages of $8.367 \%$ and $0.372 \%$ (Table 1), respectively. This may be due to that fact that as the weight of the adsorbent increased the total adsorption sites of copper reduces as a result of overlapping and aggregation of adsorption sites (Ndi Nsami et al., 2019). We assume that the aggregation of binding sites means that the binding sites had become tight clusters.

The highest removal percentage for prawn shells was seen at $20 \mathrm{mg}$ with a removal percentage of $20.49 \%$ while the lowest removal efficiency was seen at $100 \mathrm{mg}$ for prawn shells with a removal percentage of $10.65 \%$ (Table 1). An increase in biosorbent concentration increases the biosorbed metal ions because of an increase in surface area of the biosorbent (Vijayaraghavan et al., 2006).

As for cockle shells, the removal percentage was lower compared to the other shells. The highest removal percentage was at $20 \mathrm{mg}$ of cockle shells with a removal percentage of $2.628 \%$ and the lowest was observed at $100 \mathrm{mg}$ of cockle shells with a removal percentage of $-11.02 \%$ (Table 1). The negative removal percentage for $100 \mathrm{mg}$ shell weight could be an anomaly and we attribute this to the disassociation of calcium carbonate (due to the presence of hydrochloric acid in the buffer) to calcium and carbonate in which the release of copper ions could have interfered with results obtained from the use of anodic stripping voltametry.

The multifactorial ANOVA showed a significance between the removal percentage of copper and the type of shell used (Table 2). However there was no significance between the removal percentage and weights of shells. A graph was plotted to determine the estimated marginal means of the removal percentage which suggested that the removal percentage decreased as the weight of shells increased (Figure 3). Thus the following part of the experiment was conducted with shell weights of 20 and $40 \mathrm{mg}$.

Removal efficiency improves as the amount of adsorbent is increased. However, in some cases, the opposite is seen because metal ions are not able to bind with all of the exchangeable sites of the adsorbent or due to complex ion interactions, which results in a low metal uptake (Morris and Sneddon, 2011). Alwi et al. (2015) also showed that the adsorption capacity of shrimp shells increased between $10 \mathrm{mg}$ and $50 \mathrm{mg}$ but then decreased as the shell weights was increased up to $100 \mathrm{mg}$.

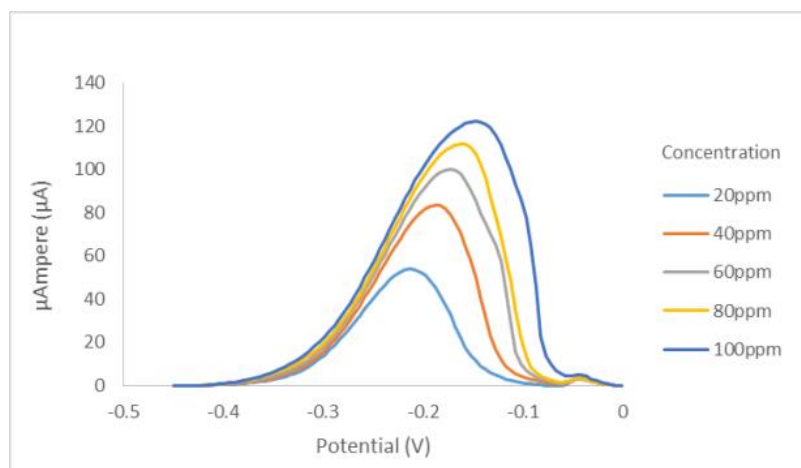

Figure 2. Differential pulse voltammograms (DPV) of copper concentration $20 \mathrm{ppm}$ to 100 ppm, measured in a working buffer of HCL/KCL $(\mathrm{pH} 4.5)$ with a scanning rate of $50 \mathrm{mV} / \mathrm{s}$. The graph begins to shift to the right beginning at 40ppm indicating a detection limit.

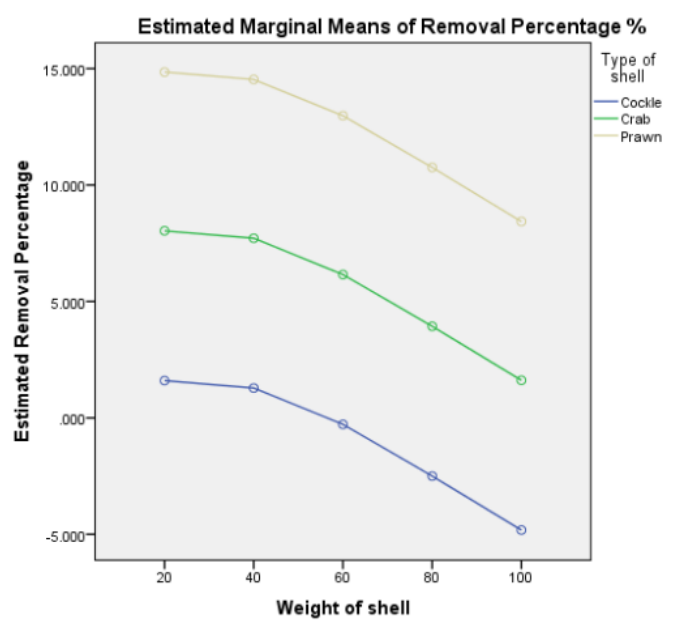

Figure 3. Estimated marginal means between removal percentage of copper and multiple weight of shells $(20,40,60,80,100 \mathrm{mg})$. The estimated means shows a large variability between the total means of 5.619 and the column means (Type of shell). 
Table 1. Removal percentage of 20 ppm of copper by different shell weights $(20,40,60,80$ and 100 $\underline{\mathrm{mg})}$.

\begin{tabular}{cccc}
\hline \multirow{2}{*}{ Weight $(\mathbf{m g})$} & \multicolumn{3}{c}{ Copper Removal Percentage (\%) } \\
\cline { 2 - 4 } & Crab Shell & Prawn Shell & Cockle Shell \\
\hline $\mathbf{2 0}$ & 8.367 & 13.488 & 2.628 \\
$\mathbf{4 0}$ & 8.134 & 13.148 & 2.247 \\
$\mathbf{6 0}$ & 4.970 & 13.119 & 0.763 \\
$\mathbf{8 0}$ & 0.372 & 11.145 & 0.670 \\
$\mathbf{1 0 0}$ & 5.603 & 10.647 & $-11.023^{*}$ \\
& $5.49 \pm 3.23$ & $12.31 \pm 1.31$ & $-0.94 \pm 5.7$ \\
\hline
\end{tabular}

*Negative results indicate that the adsorbent contaminated the samples.

Table 2. Multifactorial ANOVA for test between different weight of shells and type of shells. Dependent Variable: Removal Percentage \%

\begin{tabular}{cccccc}
\hline Source & $\begin{array}{c}\text { Type III Sum of } \\
\text { Squares }\end{array}$ & df & Mean Square & F & Sig. \\
\hline Corrected Model & $527.096^{\mathrm{a}}$ & 6 & 87.849 & 7.744 & 0.005 \\
Intercept & 473.519 & 1 & 473.519 & 41.741 & 0.000 \\
Shell & 439.191 & 2 & 219.595 & 19.358 & 0.001 \\
Weight & 87.906 & 4 & 21.976 & 1.937 & 0.198 \\
Error & 90.753 & 8 & 11.344 & & \\
Total & 1091.368 & 15 & & & \\
Corrected Total & 617.850 & 14 & & & \\
\hline
\end{tabular}

${ }^{\mathrm{a}} \mathrm{R}$ Squared $=0.853$ (Adjusted R Squared $=0.743$ )

Table 3. Removal percentage of copper by shells weighing 20 and $40 \mathrm{mg}$.

\begin{tabular}{ccccccc}
\hline \multirow{2}{*}{$\begin{array}{c}\text { Concentration } \\
(\mathbf{m g} / \mathbf{L})\end{array}$} & Crab Shell & Prawn Shell & Cockle Shell & Crab Shell & Prawn Shell & Cockle Schell \\
\cline { 2 - 7 } & 12.267 & 8.517 & $-48.795^{*}$ & 3.660 & 6.803 & $-110.465^{*}$ \\
\hline $\mathbf{1}$ & 4.605 & 18.927 & $-31.874^{*}$ & 0.951 & 5.293 & $-35.223^{*}$ \\
\hline $\mathbf{5}$ & 12.243 & 34.399 & $-6.570^{*}$ & 9.739 & 6.495 & $-11.550^{*}$ \\
\hline $\mathbf{1 0}$ & 31.220 & 31.263 & 6.753 & 21.169 & 18.282 & $-13.436^{*}$ \\
\hline $\mathbf{1 5}$ & 30.469 & 31.587 & 12.781 & 16.264 & 17.657 & $-5.555^{*}$ \\
\hline $\mathbf{2 0}$ & $18.16 \pm$ & $24.94 \pm$ & $-13.54 \pm$ & $10.36 \pm 8.45$ & $10.91 \pm 6.48$ & $-35.25 \pm$ \\
& 11.99 & 10.95 & 26.14 & & 43.52 \\
\hline
\end{tabular}

*Negative results indicate that the adsorbent contaminated the samples

\section{Removal of copper concentrations 1, 5, 10, 15,} 20 ppm with $20 \& 40 \mathrm{mg}$ shells

The crab shells at $20 \mathrm{mg}$ showed the highest removal percentage was $31.22 \%$ at $15 \mathrm{ppm}$ of copper, which then decreased to $30.469 \%$ at 20 ppm of copper (Table 3). This shows that the percentage of copper removal increases from a heavy metal concentration of $1 \mathrm{ppm}$ to $15 \mathrm{ppm}$ however the percentage decreases at higher heavy metal concentration levels. The same can be said for the crab shells weighing $40 \mathrm{mg}$ as the removal percentage decreased at $15 \mathrm{ppm}$ of copper.

The removal percentage of the prawn shells increased with the initial metal concentration but decreased as the concentration of copper increased (Table 3). With more copper content in a solution, larger fractions of active sites are involved in the adsorption process, hence the increase in removal percentage decreases (Vijayaraghavan et al., 2006). Compared to both the crab and cockle shells, the prawn shells showed the lowest standard deviation, 10.95 and 6.48 at both weights, 20 and $40 \mathrm{mg}$ (Table 3).

As for the cockle shells, although the removal percentage begins with a negative value of 48.795 , it is seen to increase as the copper concentration increases. Similar to the first test, it is likely that the disassociation of calcium 
carbonate led to the interference of copper ions within the shells. Cockle tissue is known to contain different types of heavy metals which could have led to these results (Townsend, 2010). The multifactorial ANOVA indicated a significance of 0.0001 between the types of shells and the removal percentage and this is probably due to the large difference between each shell's adsorption rate. However there is no significance when the weights $20 \mathrm{mg}$ and $40 \mathrm{mg}$ were compared (Table 4). A graph was also plotted to determine the estimated marginal means of the removal percentage which suggests that the removal percentage would be lower with $40 \mathrm{mg}$ shells (Figure 4). Additionally, traces of copper in the cockle's habitat could have possibly been incorporated with the calcium carbonate in the cockle's shell as the cockles grew in size.

The current study is a preliminary one with uncertainties such as negative readings for the cockle shell removal rate. None of the shells were pre-treated by demineralization or deproteinisation. Thus the logical explanation for the higher absorbance by prawn shells is because prawn shells are less dense compared to the crab shells because crab shells mainly constitute of calcium carbonate (Chen et al., 2008; Aklog et al., 2016). Chui et al. (1996) showed that with demineralization and deproteinisation, shrimp chitin showed removal efficiencies up to $99.6 \%$ with a copper concentration of $100 \mathrm{ppm}$. It also could be assumed that the maximum removal percentage could have been reached in less than 24 hours.

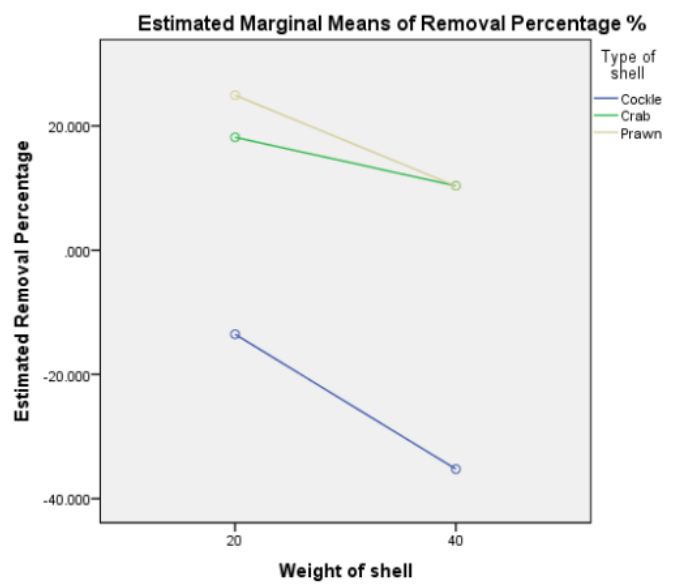

Covariates appearing in the model are evaluated at the following values: Copper Concentration $=10.20$

Figure 4. Estimated marginal means of removal percentage of copper and two weights of shell (20 \& $40 \mathrm{mg})$. The estimated means shows a large variability between the total means of 2.62 and the column means (Weight of shell) with no significant interaction between the two variables.

Table 4. Multifactorial ANOVA for test between different $20 \& 40 \mathrm{mg}$ shells with different concentrations of copper.

Dependent Variable: Removal Percentage \%

\begin{tabular}{cccccc}
\hline Source & $\begin{array}{c}\text { Type III Sum } \\
\text { of Squares }\end{array}$ & df & Mean Square & F & Sig. \\
\hline Corrected & $18497.903 \mathrm{a}$ & 6 & 3082.984 & 11.721 & 0.000 \\
Model & 3071.917 & 1 & 3071.917 & 11.679 & 0.002 \\
Intercept & 5730.552 & 1 & 5730.552 & 21.787 & 0.000 \\
Concentration & 1623.734 & 1 & 1623.734 & 6.173 & 0.021 \\
Weight & 10902.059 & 2 & 5451.029 & 20.724 & 0.000 \\
Shell & 241.558 & 2 & 120.779 & 0.459 & 0.637 \\
Weight ${ }^{*}$ Shell & 6049.588 & 23 & 263.026 & & \\
Error & 24734.372 & 30 & & & \\
Total & 24547.491 & 29 & & & \\
Corrected Total & 2459 & &
\end{tabular}

aR Squared $=.754$ (Adjusted R Squared $=0.689$ )

\section{CONCLUSION}

The current study has shown that seafood waste can be utilized to adsorb heavy metals, in this case, copper. However among the three shells, cockle shells may not be the most efficient copper biosorbent as some of the final readings had shown a higher concentration of copper which could be due to cockles being filter feeders thus whatever they consume also becomes part of their shell composition. 
More in-depth studies are needed to further prove the copper removal efficiencies of seafood waste incorporating contact time of the shells with the heavy metal solution. Comparative studies could be done to compare the removal percentage of untreated shells and treated shells as the prawn shells and crab shells contain calcium carbonate, chitin and proteins. Thus, although prawn shells and crab shells did show high removal percentages, this study does not determine if the metals were being adsorped to the proteins, chitin or the calcium carbonate from these two shells.
Townsend, M. 2010. Interactions Between Heavy Metals, Sedimentation And Cockle Feeding And Movement. [Auckland, N.Z.]: Auckland Regional Council.

Vijayaraghavan, K., Palanivelu, K. and Velan, M. 2006. Biosorption of copper (II) and cobalt (II) from aqueous solutions by crab shell particles. Bioresource Technology 97(12): 1411-1419.

Vijayaraghavan, K., Winnie, H. and Balasubramanian, R. 2011. Biosorption characteristics of crab shell particles for the removal of manganese (II) and zinc (II) from aqueous solutions. Desalination 266(1-3): 195-200.

WHO Guidelines for Drinking-water Quality. 2004. 3rd ed. [ebook] World Health Organization.

\section{REFERENCES}

Aklog, Y., Egusa, M., Kaminaka, H., Izawa, H., Morimoto, M., Saimoto, H. and Ifuku, S. 2016. Protein $/ \mathrm{CaCO}_{3} / \mathrm{chitin}$ nanofiber complex prepared from crab shells by simple mechanical treatment and its effect on plant growth. International Journal of Molecular Sciences 17(10): 1600.

Alwi, W., Firdaus, M., Syakura, H., Arief, S. and Darajat, S. 2015. Utilization of shrimp shells as biosorbent to remove heavy metal $\mathrm{Cu}$ and $\mathrm{Zn}$ in aquatic samples.

Budin, K., Subramaniam, Y., Tair, R. and Mohd. Ali, S. 2014. The ability of crab and cockle shell to adsorb lead and chromium from industrial effluent. IOSR Journal of Environmental Science, Toxicology and Food Technology 8(12): 04-06.

Chen, P., Lin, A., McKittrick, J. and Meyers, M. 2008. Structure and mechanical properties of crab exoskeletons. Acta Biomaterialia 4(3): 587-596.

Kim, S., Chung, J., Kim, T. and Cho, S. 2006. Biosorption of heavy metals and cyanide complexes on biomass. New Developments and Application in Chemical Reaction Engineering: 141-144.

Martínez-Huitle, C., Fernandes, N., Cerro-Lopez, M.A. Quiroz, M. and Quiroz, M., 2010. Determination of trace metals by differential pulse voltammetry at chitosan modified electrodes. Portugaliae Electrochimica Acta 28(1): 39-49.

Morris, A. and Sneddon, J. 2011. Use of crustacean shells for uptake and removal of metal ions in solution. Applied Spectroscopy Reviews 46(3): 242-250.

Nascimento, J., de Oliveira, J., Rizzo, A. and Leite, S. 2019. Biosorption $\mathrm{Cu}$ (II) by the yeast Saccharomyces cerevisiae. Biotechnology Reports 21: 00315.

Ndi Nsami, J. and Ketcha Mbadcam, J. 2019. The adsorption efficiency of chemically prepared activated carbon from cola nut shells by on methylene blue.

Peiselt da Silva, K. and Pais da silva, M. 2004. Copper sorption from diesel oil on chitin and chitosan polymers. Colloids and Surfaces A: Physicochemical and Engineering Aspects 237(1-3): 1521.

Pugazhenthiran, N., Anandan, S. and Ashokkumar, M. 2015. Removal of Heavy Metal from Wastewater. Handbook of Ultrasonics and Sonochemistry, pp.1-27.

Shazili, N., Yunus, K., Ahmad, A., Abdullah, N. and Rashid, M. 2006. Heavy metal pollution status in the Malaysian aquatic environment. Aquatic Ecosystem Health \& Management 9(2): 137-145.

Sudha, P., Gomathi, T., Vinodhini, P. and Nasreen, K. 2014. Marine Carbohydrates of Wastewater Treatment. Marine Carbohydrates: Fundamentals and Applications, Part B: 103-143. 